\title{
Foster Parent Stress as Key Factor Relating to Foster Children's Mental Health: A 1-Year Prospective Longitudinal Study
}

\author{
Anouk Goemans $^{1} \cdot$ Renate S. M. Buisman ${ }^{1} \cdot$ Mitch van Geel $^{1} \cdot$ Paul Vedder $^{1}$
}

Published online: 24 April 2020

(C) The Author(s) 2020

\begin{abstract}
Background Foster children are reported to often have mental health difficulties. To optimize foster children's development chances, we need to know more about the characteristics that are predictive of foster children's mental health.

Objective In the current study, we aimed to establish what accounts for the differences in foster children's mental health, by examining the change and predictors of change in foster children's mental health. Insight into foster children's mental health outcomes and their predictors could inform the design of targeted interventions and support for foster children and foster families.

Method In a sample of 432 foster children between 4 and 17 years old $(M=10.90)$ we examined a multivariate model in which characteristics of the foster child, the child's care experiences, foster family, and foster placement were included as predictors of foster children's mental health (internalizing, externalizing, and prosocial behaviors) using a threewave longitudinal design
\end{abstract}

Results Results showed that levels of mental health were generally stable over time. Differences between foster children's developmental outcomes were mainly predicted by foster parent stress.

Conclusions Foster parent stress levels were high and consistently found to be the strongest predictor of foster children's mental health outcomes. Given this finding it is important for researchers and practitioners to consider foster parent stress in screening as a point of attention in creating conditions conducive to foster children's mental health.

Keywords Foster care $\cdot$ Mental health $\cdot$ Foster parent stress $\cdot$ Longitudinal $\cdot$ Multilevel

Anouk Goemans

a.goemans@fsw.leidenuniv.nl

1 Institute of Education and Child Studies, Leiden University, Wassenaarseweg 52, 2333 AK Leiden, The Netherlands 


\section{Introduction}

Foster care is a form of child welfare wherein children who cannot be raised by their own parents are placed out-of-home and raised by foster parents. Foster care, as compared to alternatives, most closely resembles the natural home environment of a child, providing stability and continuity of caregivers and the opportunity to build close relationships with substitute parent figures (Roy et al. 2000; Tizard and Hodges 1978). Although foster care is often considered the best alternative in case of out-of-home placement (Dozier et al. 2014; Li et al. 2017), much remains unclear about the effects of foster care on children's development and discussions about its efficacy are ongoing (e.g., Ainsworth and Hansen 2014; McSherry 2018; McSherry and Malet 2017). A recent meta-analysis showed that on average foster children more often experience mental health problems than children from the general population (Goemans et al. 2016a). However, there is large heterogeneity between foster children with regard to their mental health outcomes (Goemans et al. 2015, 2016a). To optimize foster children's development, we need to know more about the characteristics that predict to foster children's positive developmental outcomes. Our focus is on foster children's mental health, because it is an important indicator of the quality of foster children's developmental trajectories and after care outcomes (Dixon 2008; Konijn et al. 2019; Oosterman et al. 2007).

To examine what accounts for different developmental outcomes of foster children, it is important to study predictors related to the foster child (e.g., age, gender), the child's care experiences (e.g., placement history, duration), the foster parents (e.g., parenting stress, thinking of quitting, parenting, SES), and the foster placement (e.g., kinship or non-kinship placements, planning for reunification) (Maaskant et al. 2014; Newton et al. 2000; Vanderfaeillie et al. 2013). These predictors are considered of interest in relation to foster children's mental health based on what is known from both developmental theories that are specific for vulnerable children, such as the ecological-transactional model of child maltreatment (Cicchetti et al. 2000), as well as from broader child developmental theories such as attachment theory (Bowlby 1969) and social learning theory (Bandura and Walters 1977). These theories and previous studies suggest that foster children's care experiences relate to mental health because a history of previous placements and duration of the current placement impact children's attachment representations (Newton et al. 2007; Rubin et al. 2007). For example, the incidence of one or more previous placements indicates the potential risk of broken attachments and unsafe attachment representations (Newton et al. 2007; Rubin et al. 2007). Moreover, the longer the duration of the current placement, the more likely it is that the foster child and foster parent build a safe and strong attachment relation which buffers against mental health difficulties. The current study is also informed by Cicchetti et al.'s (2000) ecological-transactional model. According to this model, multiple levels of a child's ecology influence each other and in turn also influence a child's development (Belsky 1993; Bronfenbrenner 1979; Cicchetti and Lynch 1993; Sameroff 2009). In order to understand foster children's development, we should therefore not only focus on child characteristics, but also on characteristics related to the foster family and the foster placement. We included several foster family (e.g., foster parent's stress, parenting, SES), and foster placement (e.g., kinship or non-kinship) characteristics that have been shown to be important for foster children's mental health (Gabler et al. 2018; Winokur et al. 2018). We also included two relatively understudied foster family and foster placement characteristics, namely 'planning for reunification' and 'thinking of quitting'. Both characteristics are likely to impact foster parents' and foster children's feelings of permanency and as a 
consequence foster children's mental health outcomes (Rubin et al. 2007; Stott and Gustavsson 2010). Foster parents who consider quitting with foster care might be less motivated to continue fostering. Decreased motivation has shown to impact the foster placement and consequently foster children's mental health outcomes (e.g., Gabler et al. 2018; Stone and Stone 1983). In addition, planning for reunification is related to foster parents' and foster children's feelings of permanency. If plans for reunification are made, both foster parents and foster children realize that the foster placement is meant to be short-term. This might impact the (investments made for the) attachment relationship (Stott and Gustavsson 2010) and consequently foster children's mental health. The current study aimed to examine characteristics related to the foster child, the child's care experience, the foster family, and the foster placement in relation to foster children's mental health. By using a longitudinal design, we try to gain more insight in foster children's mental health outcomes and individual differences over time.

The majority of studies on foster children's development and its predictors are of crosssectional nature (e.g., Clausen et al. 1998; Lehmann et al. 2013). Cross-sectional studies can establish foster children's functioning and examine which characteristics or circumstances are correlated with either desired on undesired outcomes. However, cross-sectional studies cannot establish change and predictors for change, and hence, are unable to capture the risk and protective factors that are linked to improvement or deterioration of foster children's developmental outcomes. Longitudinal research is needed to more fully understand the developmental outcomes of foster children and to gain insight in the characteristics or factors that predict their development (Cuddeback 2004; Holtan et al. 2005; McSherry and Malet 2017). Several longitudinal studies on foster children's development have been conducted to date. The results of these studies with respect to the developmental outcomes of foster children have not been conclusive (see for a meta-analysis Goemans et al. 2015). Some studies found improved mental health outcomes for foster children over time (e.g., Ahmad et al. 2005; Barber and Delfabbro 2005; Fernandez 2009), while others did not replicate these results (e.g., Leathers, Spielfogel et al. 2011; Perkins 2008) or even found that foster children's mental health deteriorated over time (e.g., Fanshel and Shinn 1978; Frank 1980; Lawrence et al. 2006).

Few existing longitudinal studies have focused on a combination of predictors in relation to foster children's development (see for a good example Hiller and Clair 2018). Simultaneously including a broad range of predictors in a multivariate model could help to identify the strongest predictors of the development of children in foster care (Oosterman et al. 2007; Tarren-Sweeney and Goemans 2019). However, multivariate modeling presents a challenge in that it requires a considerable sample size to ensure adequate power (Tabachnick et al. 2007). Moreover, longitudinal research on children in foster care can be difficult in terms of recruitment, data collection, and follow-up (Jackson et al. 2012; Maaskant 2016), and is often characterized by high attrition rates and missing data (Goemans et al. 2015; Jackson et al. 2012; Tarren-Sweeney 2017). Advanced techniques to handle missing data provide a solution, because especially for studies with large amounts of missing data, these techniques produce less biased estimates of missing values compared to other more conventional methods (Graham 2009). These techniques enable both the focus on general developmental trends as related to a single predictor, and a on a broader range of predictors in a multivariate model (Van Oijen 2010).

In the current study, we aim to establish why some foster children have mental health difficulties while others do not, by examining the change and predictors of change in foster children's mental health. We examined a multivariate model in which characteristics of the foster child, the child's care experiences, foster family, and foster placement are included 
as predictors of foster children's mental health (internalizing, externalizing, and prosocial behaviors) using a three-wave longitudinal design and applying multiple imputation. The inclusion of predictors in the current study is informed by developmental theories and findings from previous research. We included a few relatively understudied predictors (e.g., planning for reunification and foster parents' thinking of quitting) for which it is hypothesized that they are predictive of foster children's feelings of permanency and consequently also their mental health outcomes (Rubin et al. 2007; Stott and Gustavsson 2010). Selected characteristics related to the child's experiences with care are placement history and duration of the placement. Selected foster family and foster placements characteristics are type of foster family, foster parents' thinking about quitting foster care, SES, foster parent stress, parenting practices and strategies, and planning for reunification (Chamberlain et al. 2008; Maaskant et al. 2014; Winokur et al. 2018). It is hypothesized that both foster child, the child's care experiences, foster family, and foster placement characteristics will be predictive of foster children's mental health outcomes, with the latter two being more strongly related to the outcomes because this has been shown in previous research (Goemans et al. 2016b).

\section{Method}

\section{Participants}

Participants in this study were foster parents who completed a questionnaire on foster child, foster family, and foster placement characteristics. They provided information on 432 foster children who resided in regular, formal foster care in the Netherlands. Foster children (46.8\% girls) were between 4 and 17 years old $(M=10.90, S D=3.81)$. Approximately two thirds of the foster children resided in non-kinship foster care (66.9\%). Foster children experienced on average 1.20 previous foster placements $(S D=1.55$, range $0-13)$, with $36.7 \%$ of the foster children experiencing no previous placements, $34.3 \%$ experiencing one previous placement, $15.6 \%$ experiencing two previous placements, $8.0 \%$ experiencing three previous placements, and $5.4 \%$ experiencing four or more placements. Foster children's mean time in the current foster placement at the first wave was 58.98 months $(S D=50.61$, range $0-214$ months), with $19.1 \%$ of the children being in their current placement for less than 1 year, $12.3 \%$ for 1 to 2 years, $11.1 \%$ for 2 to 3 years, $8.9 \%$ for 3 to 4 years, $8.7 \%$ for 4 to 5 years, $6.5 \%$ for 5 to 6 years, $6.3 \%$ for 6 to 7 years, $5.1 \%$ for 7 to 8 years, $4.6 \%$ for 8 to 9 years, $3.1 \%$ for 9 to 10 years, $3.9 \%$ for 10 to 11 years, and $10.4 \%$ for more than 11 years with a maximum of almost 18 years (214 months).

\section{Procedure}

All foster care agencies in the Netherlands $(N=28)$ were invited to participate in this study. Seven agencies (25\%) agreed to participate. The participating agencies were well spread across the Netherlands and differed on various characteristics (large vs. small, secular vs. non-secular). The main reason for foster care agencies to not participate was to prevent a research overload for their foster families because of their participation in other studies. Foster parents within the participating foster care agencies were informed about the study objectives by their agency. Foster care agencies asked foster parents' consent to participate and we received the contact information for those foster parents who gave consent. 
In October 2014 we started our longitudinal study in which we followed foster children and their foster families for 12 months. There were three measurements, separated by six month intervals (Wave 1: October 2014, Wave 2: April 2015, Wave 3: October 2015). To ensure that the same foster parent completed each wave and to connect responses over the waves to the correct participant we sent out invitations to complete the questionnaire using a personal link. After data collection, each foster parent received a unique numerical ID and personal data was deleted from the data file. At each wave foster parents were asked to report the birth date of the foster child. We compared these birthdays across every collected wave to ensure that foster parents had consistently reported about the same foster child.

A total of 1387 foster families were invited to participate in the first wave of the study. Most invitations were sent by email. However, we sent some paper questionnaires (5.2\%) to foster families for whom the email address was not known by the foster care institution. Two reminders were sent to complete the questionnaire. All foster parents who participated in Wave 1 were also invited to participate in both Wave 2 and Wave 3. The initial sample that participated in Wave 1 consisted of 549 children. We excluded foster children who resided in part-time foster care and who fell outside the age range of 3-17 years, resulting in a final sample of 432 foster children. For the goal of this paper, we only selected children from age 4 onwards because the measure we used to measure children's mental health (i.e., the SDQ) is meant for children between 4 and 17 years old. The participation rate was $51.6 \%$ for Wave 2 and $42.3 \%$ for Wave 3. All foster children came from different foster families, i.e., we did not include multiple foster children who resided in the same foster family. The [name withheld for peer review] Ethics Review Board approved the study prior to the data collection.

\section{Instruments}

\section{Mental Health}

To measure foster children's mental health, the Dutch version of the Strengths and Difficulties Questionnaire was used (SDQ; Goodman 1997; Van Widenfelt et al. 2003). The SDQ is a 25-item questionnaire answered on a 3-point Likert scale ranging from 0 (not true) to 2 (very true). SDQ scores were generated in SPSS using the SDQ syntax as provided on the SDQ website (https://www.sdqinfo.com/c1.html). The 25 items were combined into three subscales as suggested by Goodman et al. (2010): internalizing behavior problems, externalizing behavior problems, and prosocial behavior. Higher scores on these subscales represent more internalizing and externalizing problems, and better prosocial behaviors. The subscale internalizing behavior problems is formed by combining the ten items for emotional and peer problems. Sample items are: 'often unhappy, downhearted, or tearful' and 'rather solitary, tends to play alone'. The subscale externalizing behavior problems consists of ten items for conduct and hyperactivity problems. Items are for example 'generally obedient, usually does what adults request' and 'easily distracted, concentration wanders'. The subscale prosocial behavior contains five items and a sample item is: 'Shares readily with other children'. Previous research has shown good psychometric properties, both internationally (Achenbach et al. 2008; Goodman et al. 2010; Van Widenfelt et al. 2003) and in the Netherlands (Muris et al. 2003; Van Widenfelt et al. 2003). In the current study, Cronbach's alphas for the waves $1-3$ were $0.79,0.79$, and 0.76 for internalizing, 0.85 , 
0.83 , and 0.85 for externalizing problems, and $0.75,0.72$, and 0.77 for prosocial behavior, respectively.

\section{Characteristics of the Foster Child, the Child's Care Experiences, and the Foster Family}

Foster parents were asked to provide information about several foster child characteristics (e.g., age, gender), the child's care experiences (placement history, duration of the current placement), and foster family and foster placement characteristics (e.g., SES, type of foster family, whether foster parents were thinking about quitting foster care, planning for reunification). Whether the respondent thought about quitting was inquired with the question "do you ever think about quitting as a foster parent?" which could be answered on a four point Likert scale ("often”, "sometimes", "barely", "never"). Information about planning for reunification was collected with the question "are there plans to reunify the child with the biological parents?", to be answered with "yes" or "no". For both questions, parents could also indicate that they did not know, which was then considered missing data. Foster parents completed the four item Family Affluence Scale (FAS) to measure SES (Currie et al. 1997), for which we computed a composite score ranging from 0 to $9(M=6.19$, $S D=1.50$ ) (Boyce et al. 2006). The FAS has been found to be a valid measure of children's SES (Andersen et al. 2008; Boyce, et al. 2006). In addition, foster parents reported their highest level of completed education. Approximately $20 \%$ of foster parents completed primary school or secondary school. Approximately $40 \%$ completed secondary vocational education, approximately $30 \%$ completed higher vocational education (university of applied sciences), and approximately $10 \%$ holds a university degree. The information of the FAS and foster parents' education were standardized to ensure that both measures had an equal weight in the composite score and subsequently combined to create one SES variable, to be used as a control variable.

\section{Parenting}

The Dutch version (Van Lier and Crijnen 1999) of the Alabama Parenting Questionnaire (APQ; Frick 1991; Shelton et al. 1996) was used to measure foster parents' parenting behavior. The APQ consists of 42 items that foster parents have to evaluate on a 5-point Likert scale ranging from 1 (never) to 5 (always). The APQ measures five dimensions of parenting: positive involvement with children (10 items, sample item: 'You play games or do other fun things with your child'), use of positive discipline techniques (6 items, sample item: 'You reward or give something extra to your child for obeying you or behaving well'), poor monitoring and supervision (10 items, sample item: 'You don't tell your child where you are going'), inconsistency in the use of discipline (6 items, sample item: 'The punishment you give your child depends on your mood') and use of corporal punishment ( 3 items, 'You slap your child when he/she has done something wrong'). Additionally, seven items deal with 'other discipline practices', which do not form a scale but give additional information on parenting on an item by item basis. For the current study we combined the first two scales (i.e., positive involvement and positive discipline) and the other three scales (poor monitoring and supervision, inconsistency, corporal punishment) into two new scales which reflect positive and negative parenting (Goemans et al. 2018b). With respect to the psychometric properties, previous research has shown the APQ to be a valid questionnaire to identify different styles of parenting (Dadds et al. 2003; Elgar et al. 
2007). Cronbach's alphas in this study for Waves $1-3$ were $0.69,0.66$, and 0.66 for positive parenting and $0.78,0.78$, and 0.81 for negative parenting, respectively.

\section{Parenting Stress}

To measure foster parent stress we used the short version of the Nijmeegse Ouderlijke Stress Index (NOSI-K; De Brock et al. 1992), which is based on the Parenting Stress Index (PSI; Abidin and Abidin 1990). The NOSI-K consists of 25 items which can be answered on a 6-point Likert scale ranging from 1 (totally disagree) to 6 (totally agree). A sample item is: 'Child is more of a problem than expected'. Internal consistencies of the NOSI-K have been reported to be high (De Brock et al. 1992; Haskett et al. 2006), and the NOSI-K has been previously used in studies on foster parents (Maaskant et al. 2016; Murray et al. 2011; Nilsen 2007; Van Andel et al. 2015). In the current study the internal consistency for all three waves was 0.96 .

\section{Data Analysis}

The goal of this study was to examine the change in foster children's mental health over time and how this change depends on foster child, care experiences, foster family, and foster placement characteristics. Multilevel modeling was used to deal with the hierarchical data structure (i.e., the same children are measured over time, causing mental health scores within an individual foster child to be correlated) and allows to examine within-person differences (Singer et al. 2003). The statistical software R was used for the analyses (R Core Team 2018). Continuous predictor variables were centered around their mean to allow easier interpretation of intercept and slope parameters (Enders and Tofighi 2007; Peugh 2010).

Missing data for the second and third wave were approximately 51 and $58 \%$ respectively for the different variables included in our model $\left(M_{\text {missingWave2 }}=50.85\right.$; $\left.M_{\text {missingWave3 }}=57.95\right)$. We performed Little's MCAR test which indicated that the missing data were missing completely at random $\left(\chi^{2}(1383)=1383.12, p=0.49\right)$. We also performed t-test and chi-square tests to compare the foster children who participated in Wave 1 only to the foster children who participated in Wave 1 and Wave 2 and/or Wave 3 on several variables. T-tests (for age, placement duration, placement history, SDQ, NOSI$\mathrm{K}, \mathrm{APQ}$ ) and chi-square tests (gender, kinship vs. non-kinship, reunification, quitting) revealed two differences between the groups. A plan for reunification was more often made for foster children participating in Wave 1 but not in Wave 2, than for foster children participating in Wave 1 and Wave $2\left(\chi^{2}(1)=7.52, p=0.006\right)$. Also, a plan for reunification was more often made for foster children participating in Wave 1 and 2 but not in Wave 3 than for foster children participating in all Waves $\left(\chi^{2}(1)=12.90, p<0.001\right)$. Also, foster parents participating in Wave 1 and 2, but not in Wave 3 were more likely to think about quitting foster care than foster parents participating in all Waves $\left(\chi^{2}(1)=4.03, p=0.045\right)$. For the other variables, we found no differences between those who did and those who did not drop out between waves.

Conventional methods to handle missing data (e.g., pairwise or listwise deletion) are wasteful and may lead to biased or even false results due to a loss of power (Graham 2009; Rubin 1987; Schafer and Graham 2002), and therefore we used multiple imputation to adequately deal with missing data (Van Ginkel et al. 2019). Multiple imputation is less biased especially for larger percentages of missing data because wider confidence intervals are generated for variables with more missing data, avoiding the risk of false positives (Graham 
2009). Given the hierarchical structure of our data, we first tried multilevel multiple imputation with the mice and pan packages. However, this resulted in estimates far outside the expected range and autocorrelation function (ACF) plots (Azur et al. 2011) revealed that imputations did not converge (Grund et al. 2016). We therefore continued with single level multiple imputation in the mice package. Missing data were imputed 100 times, with 100 iterations for each imputation. We used predictive mean matching (PMM) as an imputation method. PMM predicts the missing values and subsequently selects observed values which are used to replace the missing values (Heymans and Eekhout 2019). Autocorrelation function (ACF) plots revealed that all imputations converged. In addition, the correlations between variables were approximately the same in the imputed datasets compared to the non-imputed dataset (see Table 1).

The mice and mitml packages in $\mathrm{R}$ were used to fit a (pooled) multilevel model to our multiple imputed dataset and to pool the results (Groothuis-Oudshoorn and Van Buuren 2011; Grund et al. 2016). Using the pooled data, we first tested three consecutive models that increased in complexity. First, we tested the unconditional means model (Model 1) with and without quadratic time effect to compute the intraclass correlation (ICC) and decompose the variance within and between persons. We then added time as predictor and tested the unconditional growth model - random intercepts only (Model 2), and the unconditional growth model - random intercepts and slopes (Model 3). These unconditional multilevel models show whether there is systematic variation in foster children's mental health outcomes worth exploring, and where that variation resides (within or between subjects). In the fourth, fifth, and sixth model, we successively added the covariates (e.g., age and gender) and child's care experiences (block 1), and foster family and foster placement (block 2) characteristics. Additionally, these factors were controlled for in the second and third step (foster family and foster placement characteristics respectively). Likelihood ratio tests were used to evaluate whether model fit improved (Grund et al. 2016). Significant covariates or predictors were kept in the model when testing subsequent models, resulting in a final parsimonious model (Model 7).

\section{Results}

An overview of the descriptive statistics and correlations is presented in Table 1. Foster children's mean total behavior problems, the sum of their internalizing and externalizing problems, $\left(M_{\text {Wave } 1}=12.57, S D_{\text {Wave } 1}=6.94 ; M_{\text {Wave2 }}=12.84, S D_{\text {Wave2 }}=7.06 ; M_{\text {Wave3 }}=12.11\right.$, $S D_{\text {Wave3 }}=6.96$ ), fell within the borderline range following the Dutch norm cut-off scores (Goedhart et al. 2003). With regard to the total behavior problems, 42.4\%, $42.0 \%$, and $51.1 \%$ of the scores fell within the normal range (range 0-10) for the three consecutive waves, whereas $12.8 \%, 14.5 \%$, and $15.4 \%$ fell within the borderline range (range 11-13), and $44.8 \%, 43.5 \%$, and $33.5 \%$ within the clinical range (range 14-40). Correlations for most variables were in the expected direction and significant. It was found that age was positively related to duration of the placement, and higher levels of internalizing and externalizing behaviors corresponded to higher levels of parental stress. We also found a negative relation between positive parenting and negative parenting. Furthermore, the constructs that were measured over time (parenting, foster parent's stress, and internalizing, externalizing and prosocial behavior) showed strong positive correlations over time. We did not find any significant correlations for placement history. 


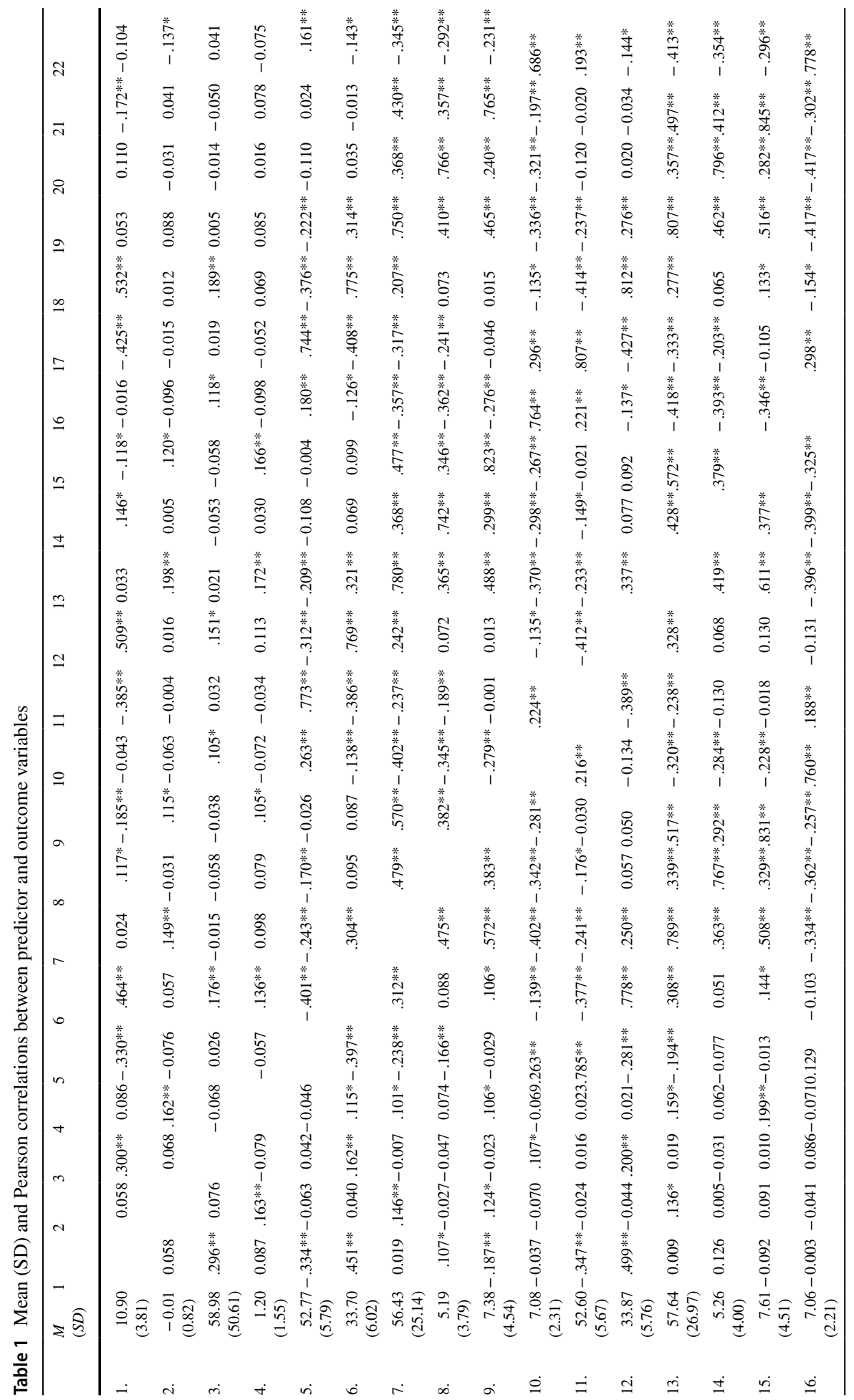




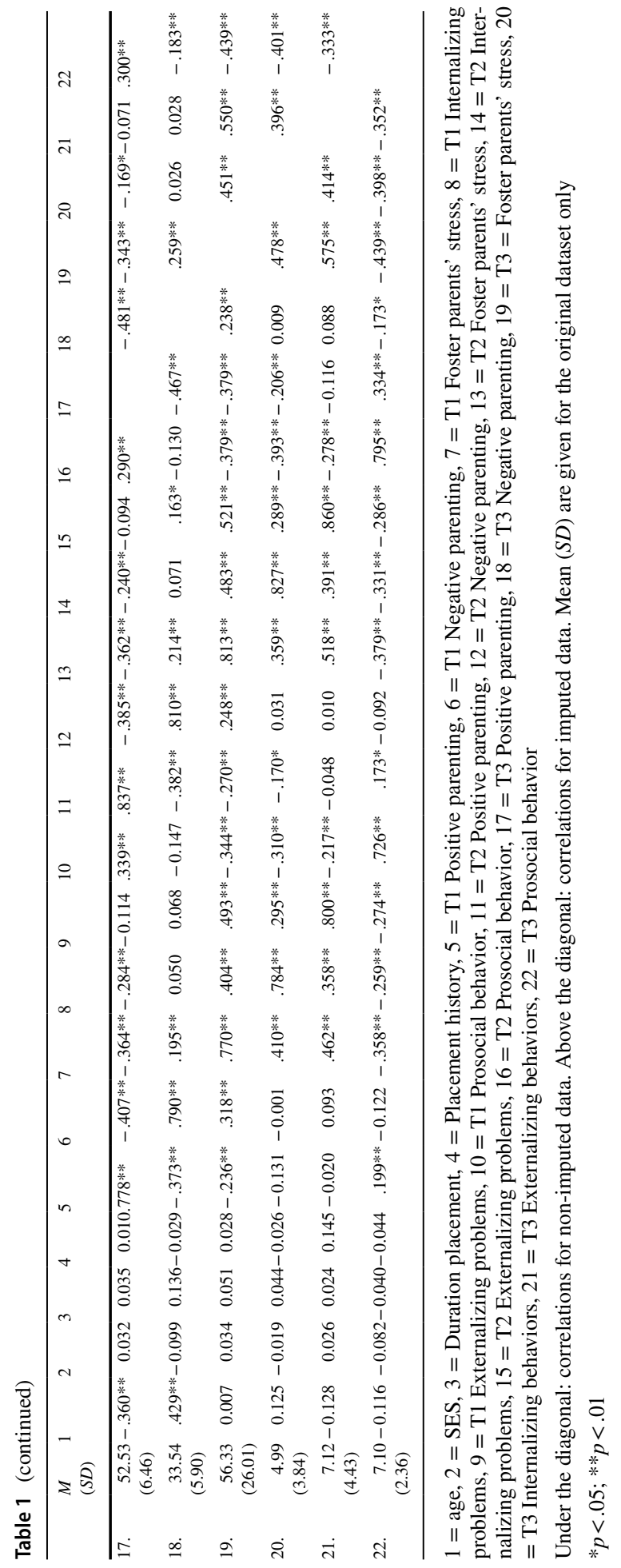




\section{Prosocial Behavior}

The results of the multilevel models on prosocial behavior are presented in Table 2. Based on the first model, we estimated the intra-class correlation (i.e., the correlation between measurements of the same child) being 0.74 . This means that approximately three-quarters of the total variance in prosocial behavior pertains to differences between foster children prosocial behavior scores. This implies that large differences exist between children in their average prosocial behavior scores (averaged across time) compared to the differences in prosocial behavior scores within a child (variation over time within a child). Model 2 showed no increasing or decreasing trend in prosocial behavior over time. In other words: there was no effect of time. The likelihood ratio test (LRT) indicated that Model 2 did not fit the data better than Model $1\left(\chi^{2}(d f=1)=0.01, p=0.92\right)$. In Model 3 we tested whether foster children differ in their intercepts and slopes. There was a significant improvement when comparing model 3 to model $2\left(\chi^{2}(d f=2)=6.10, p=0.002\right)$, meaning that children differed in the rate of change of prosocial behavior. Model 4 did not fit the data better than model $3\left(\chi^{2}(d f=2)=0.67, p=0.51\right)$, and showed that there were no main effects of the covariates age and gender, so these were removed from the model. In the fifth model, we added the block 1 predictors (e.g., child's care experiences characteristics). Neither placement history nor the duration of the foster placement was significantly related to foster children's prosocial behavior. Model 5 did not fit the data significantly better than model $3\left(\chi^{2}(d f=2)=2.30, p=0.10\right)$. In the sixth model, we added the foster family and foster placement characteristics, which led to a significant improvement compared to model 3 $\left(\chi^{2}(d f=7)=12.80, p<0.001\right)$. Type of placement was a significant predictor of prosocial behavior, with foster children in kinship foster families showing more prosocial behavior than foster children in non-kinship foster families $(b=-0.43, p<0.01)$. In addition, foster parent stress predicted foster children's prosocial behavior, with high foster parent stress related to lower prosocial behaviors $(b=-0.02, p<0.001)$. Lastly, positive foster parenting was related to higher levels of prosocial behavior $(b=0.06, p<0.001)$. The final parsimonious model, Model 7, with only the significant predictors included, is presented in Table 2.

\section{Internalizing Behavior Problems}

The results for the multilevel models on internalizing behaviors are displayed in Table 3. Based on the first model, the intra-class correlation was estimated 0.77 , indicating that $77 \%$ of the total variance (i.e., differences) in internalizing behaviors pertains to differences between foster children, meaning that there are large differences between foster children's internalizing behavior levels. Model 2 showed that there was no increase or decrease in internalizing behavior over time and Model 2 did not fit the data better than Model $1\left(\chi^{2}(d f=1)=0.01, p=0.93\right)$. In Model 3 we tested whether foster children differed in their intercept and slopes, which appeared not to be the case $(\chi 2(d f=2)=0.59, p=0.55)$. Although Model 3 did not seem to fit the data better than Model 2, we decided to continue with Model 3 because keeping a (non-significant) random slope in the model allows for extra modeling flexibility while not harming the estimates for the other model parameters. In Model 4, the covariates age and gender were added. Age significantly predicted internalizing behaviors such that older children showed more internalizing problems $(b=0.12$, $p=0.01)$. Age was therefore kept in the model. Model 4 also fitted the data significantly better than Model 3, $(\chi 2(d f=2)=4.48, p=0.01)$. In Model 5, we found that neither of the 


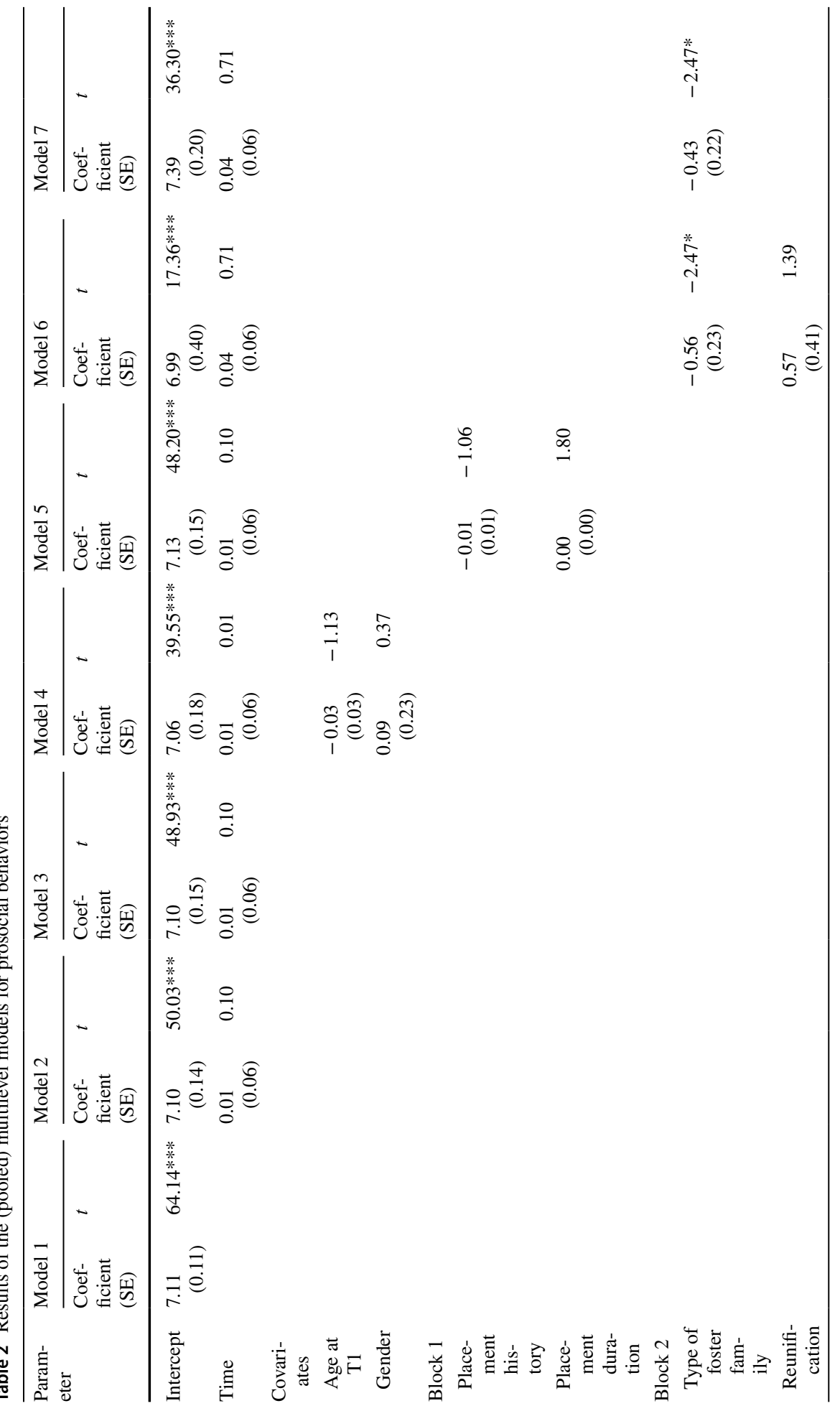




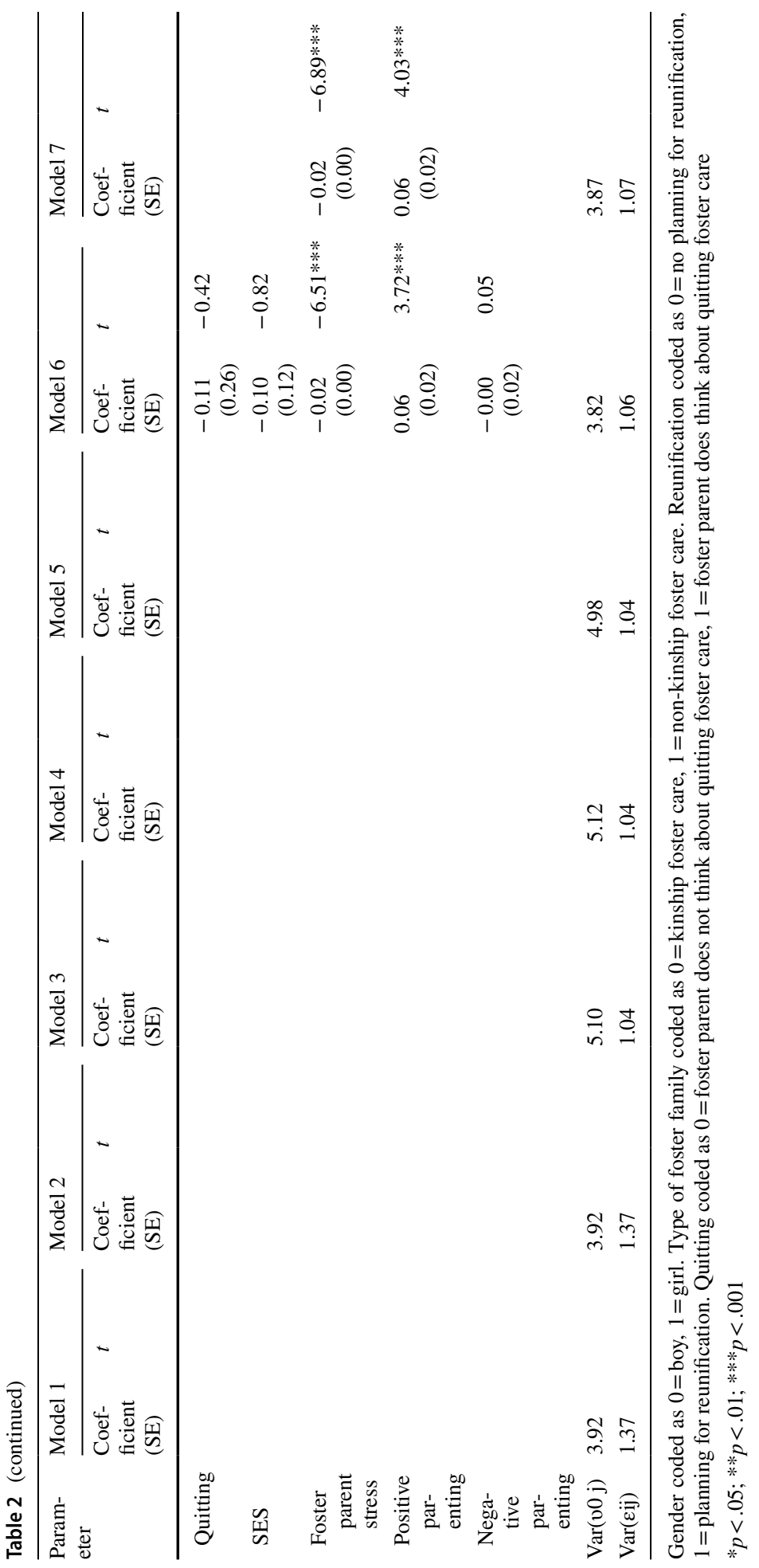




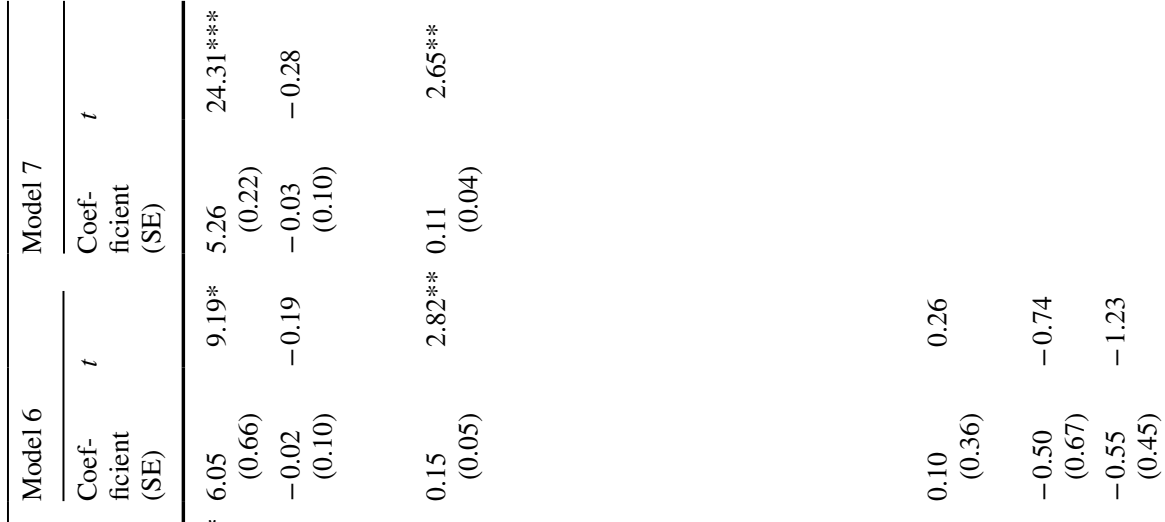

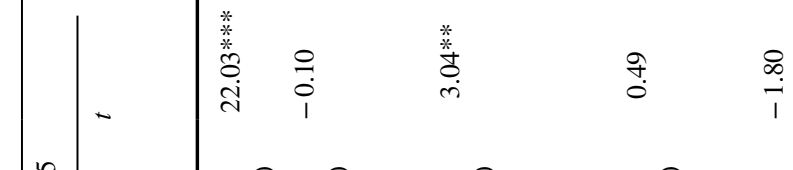

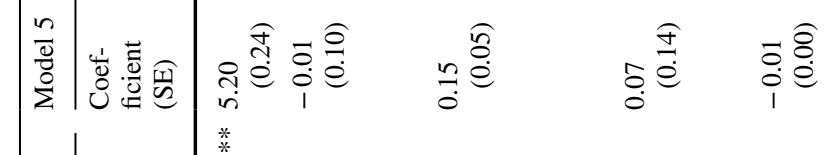

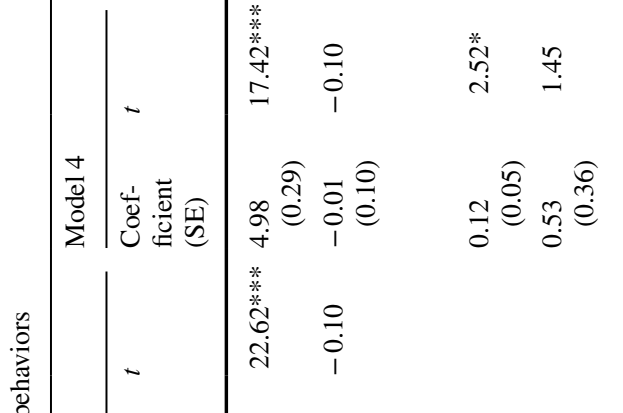

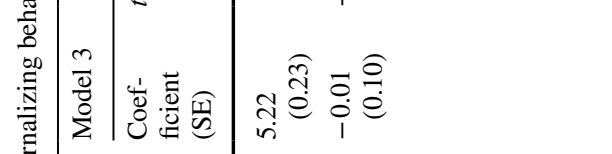

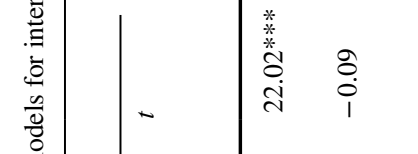

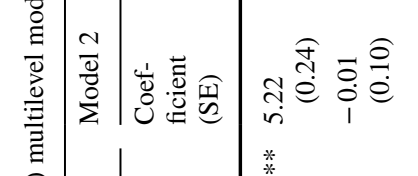

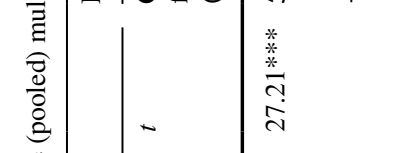

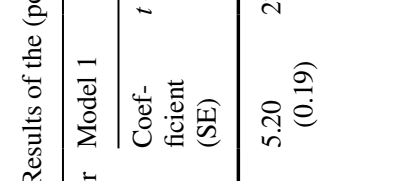

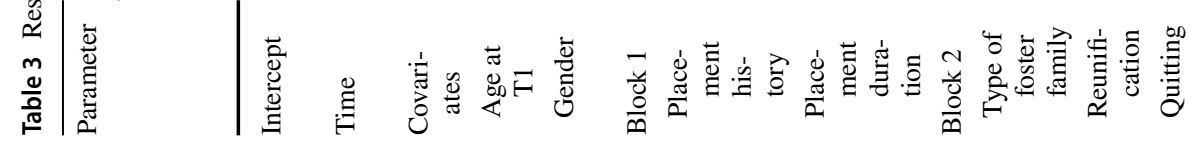

\section{基 Springer}




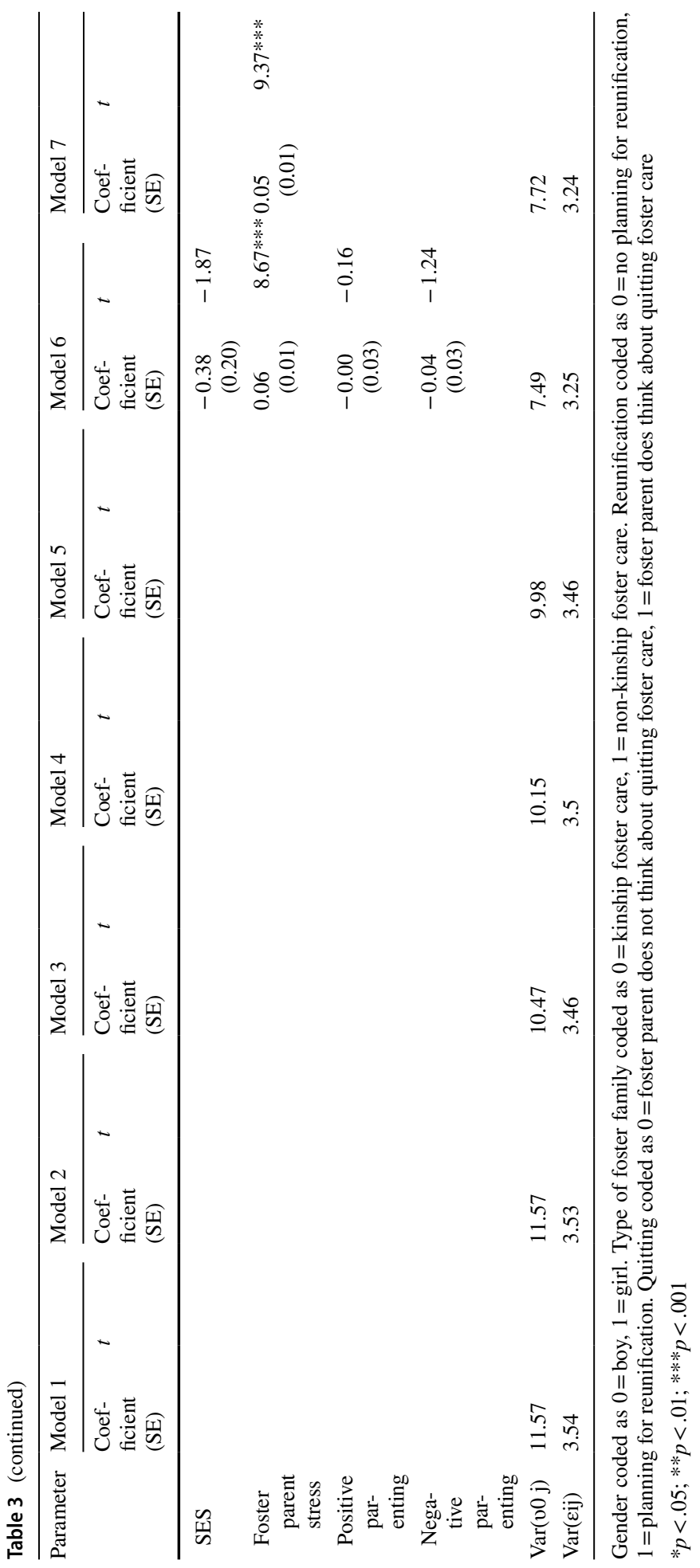


two child's care experience characteristics (i.e., placement history and placement duration) significantly predicted internalizing problems and that Model 5 did not fit the data significantly better than Model 4, $(\chi 2(d f=1)=1.51, p=0.22)$. Child's care experience characteristics were therefore removed from the model. Model 6, with the foster family and foster placement characteristics included, resulted in a significant model improvement compared to Model $4\left(\chi^{2}(d f=6)=16.00, p<0.001\right)$. Foster parent stress was a significant predictor $(b=0.06, p<0.001)$, indicating that lower parenting stress was related to fewer internalizing behaviors. The results for the final parsimonious Model 7, with only the significant predictors included, can be found in Table 3.

\section{Externalizing Behavior Problems}

The last set of multilevel models was run for externalizing behaviors. The results are presented in Table 4. Model 1 indicated that more than $80 \%(\mathrm{ICC}=0.81)$ of the total variance in externalizing behaviors pertains to differences between foster children, indicating that large differences exist between foster children's average externalizing behavior scores compared to the differences in externalizing scores within a child. Model 2 showed no increasing or decreasing trends in externalizing behaviors over time $(\chi 2(d f=1)=1.90, p=0.17)$. Model 3 indicated a significant improvement compared to Model $2\left(\chi^{2}(d f=2)=6.74\right.$, $p=0.001$ ), indicating difference in the rate of change of externalizing behavior. In Model 4 , we added the covariates age and gender of which age appeared to be significant $(b=-0.19$, $p=0.001$ ), with older children showing fewer externalizing behavior problems. Age was therefore retained in the model. Model 4 showed a significant improvement compared to Model $3\left(\chi^{2}(d f=2)=5.51, p<0.01\right)$. In Model 5, we added placement history and placement duration, but neither was a significant predictor and Model 5 did not fit the data better than Model $4\left(\chi^{2}(d f=1)=2.65, p=0.10\right)$. Model 6 included foster family and foster placement characteristics and resulted in a better fit than Model 4, $\chi 2(d f=6)=28.00$, $p<0.001$. It yielded a positive effect of foster parent stress, with higher stress correspondingto higher levels of externalizing behavior problems $(b=0.08, p<0.001)$. The final parsimonious model, Model 7, included the significant predictors (age, foster parent stress) and is presented in Table 4. Model 7 did not fit the data better than Model $6\left(\chi^{2}(d f=6)=1.06\right.$, $p=0.38$ ).

\section{Discussion}

The aim of this study was to examine change in foster children's mental health over time and how this change depends on characteristics related to the foster child, the child's care experiences, foster family, and foster placement. Foster children's mental health is an important predictor of foster placement success (Konijn et al. 2019). We found that levels of mental health were stable over time, meaning that, on average, there were no increasing or decreasing trends in prosocial, internalizing, and externalizing behaviors during the one year study period. This is in line with the meta-analysis of Goemans et al. (2015) that analyzed over thirty longitudinal studies on foster children's behavioral development and found no increases or decreases in mental health problems. Furthermore, our finding is in line with the recently published five-year longitudinal study of Hiller and Clair (2018). Hiller and Clair (2018) used growth mixture modeling, a method to identify clusters of foster children showing similar patterns of mental health over time. They found that for most 


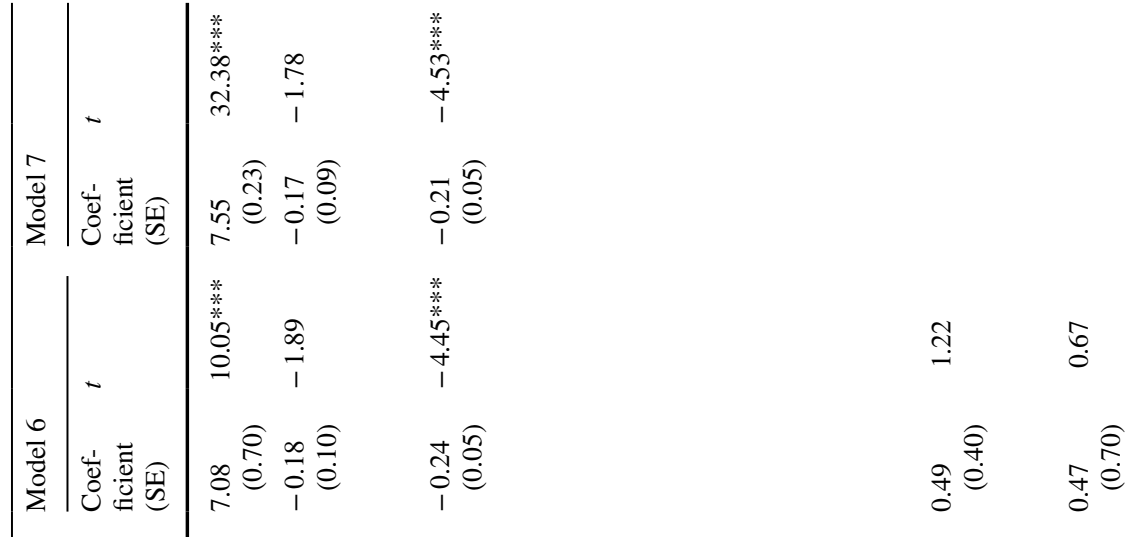

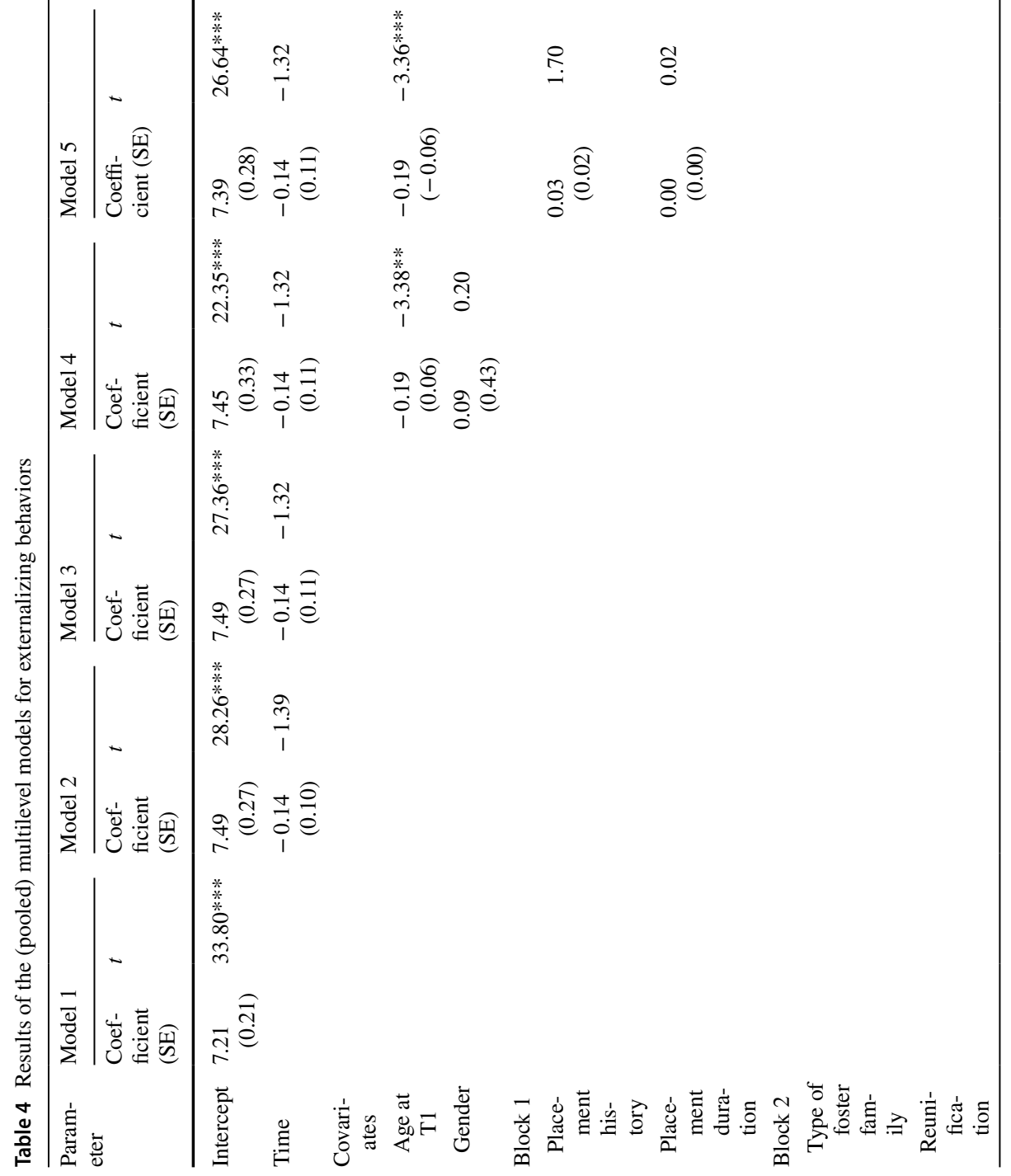




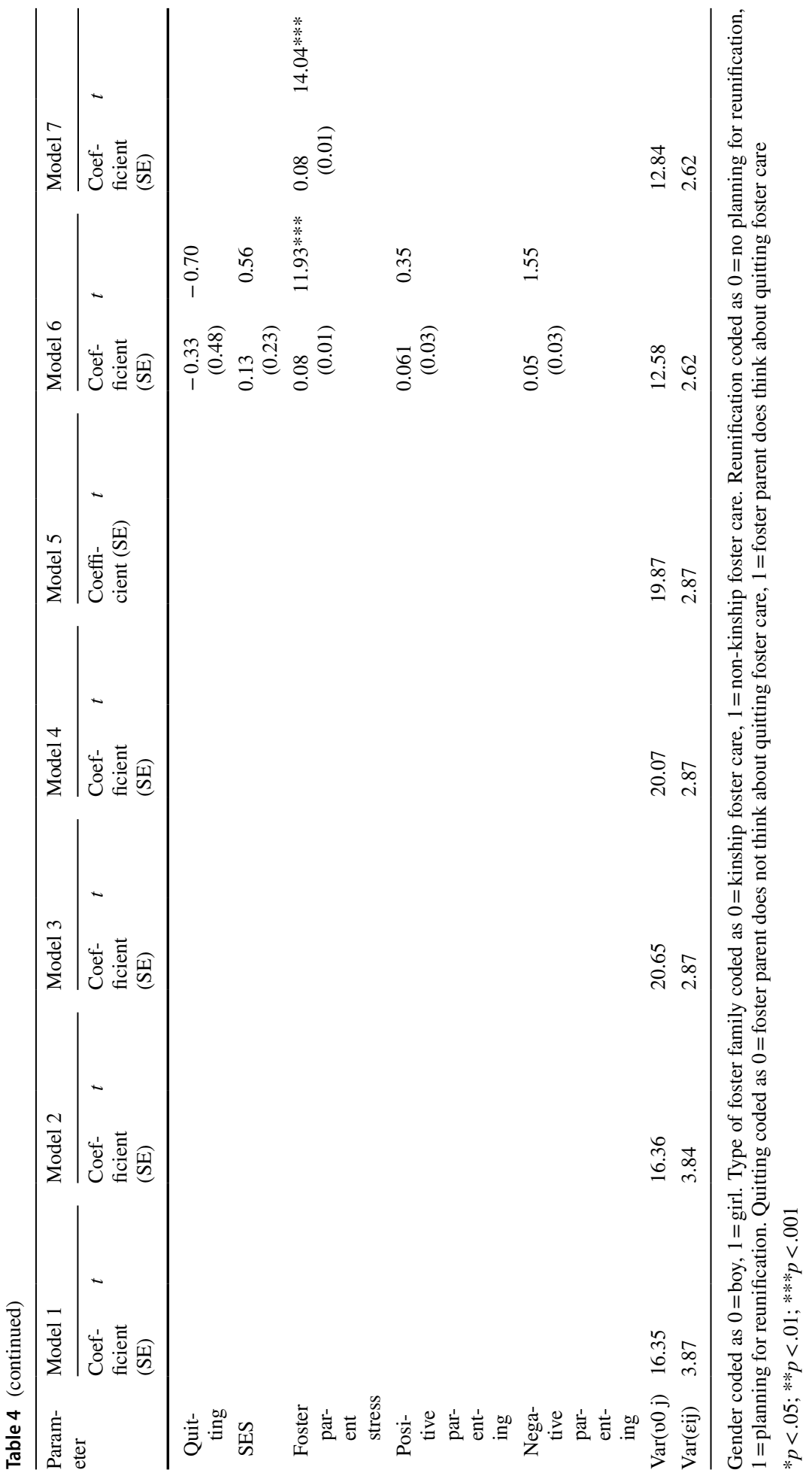


mental health domains the largest trajectories (i.e., the cluster containing most foster children) were stable, with no improvement or deterioration over the five-year study period. Moreover, for each mental health domain, the majority of the children fell into categories that showed stability over time (Hiller and Clair 2018).

Despite this stability, previous longitudinal studies and our study showed that foster children show different levels of internalizing, externalizing and prosocial behaviors. Foster children varied in their levels of mental health, and for prosocial and externalizing behavior the change over time varied also between foster children. In other words, there were differences between foster children's developmental outcomes with respect to prosocial and externalizing behavior. Heterogeneity in foster children's development was also shown in a 7-to-9-year longitudinal study by Tarren-Sweeney (2017). Although foster children's mean scores on average did not change, different groups of foster children showing similar patterns of mental health difficulties were distinguished. For example, $60 \%$ of the foster children manifested either sustained mental health or meaningful improvement in their mental health. The study of Hiller and Clair (2018) also showed that although most children showed stable trajectories of mental health, there were also 'latent trajectories' (symptoms started in the normal range and significantly increased to the abnormal range). These findings illustrate that although foster children's development on average seems to be stable, foster children are a diverse group. Besides studying general trends in foster children's development, it is important to take the heterogeneity of foster children's developmental trajectories into account when studying their development (Tarren-Sweeney 2017).

Given this heterogeneity the current study examined what accounts for different developmental outcomes by studying predictors of mental health outcomes. We simultaneously included a broad range of characteristics related to the foster child, child's care experiences, foster family, and foster placement in the analyses. Foster parent stress was consistently found to be the strongest predictor of foster children's mental health outcomes. Increased stress as reported by the foster parents was related to lower levels of foster parent reported prosocial behavior and higher levels of internalizing and externalizing problems. It is important to note that foster parents were the sole informants in this study and reported both on their own stress and the foster child's mental health. This potentially resulted in an overestimation of the association between variables of interest (Keijsers et al. 2012; O'Connor 2002). Nonetheless, our study suggests that foster parent stress and foster children's mental health are correlated, which is in line with previous research (e.g., Kelley et al. 2011; McSherry et al. 2018; Murray et al. 2011). However, only a few longitudinal studies have examined the directionality of the effects (Gabler et al. 2018; Goemans et al. 2018a; Lohaus et al. 2018). These studies found significant weak to moderate correlations between stress of parents at the first time point and mental health of foster children at a later time point. Two of these studies (Goemans et al. 2018a; Lohaus et al. 2018) tested this relation in a multivariate model using structural equation modeling, and found no significant prospective pathways from foster parent stress to foster children's behavior problems, meaning that foster parent stress did not predict foster children's mental health. As Lohaus et al. (2018) suggested, identifying prospective pathways might be difficult if most variance of later assessments is already explained by the previous assessments, which is shown by the high stability across assessments. Moreover, both studies showed weak to moderate concurrent relations between foster parent stress and foster children's behavior problems. Nevertheless, foster parent stress is an important factor to take into account when looking at foster children's mental health. Although the predictive value of foster parent stress on foster children's mental health might be small, the two factors are correlated. This means that 
in case of studying or identifying either foster parent stress or foster children's mental health, researchers and practitioners should be aware of possible co-occurrence and provide social support when necessary (Cooley et al. 2019).

We also found that the type of placement and positive parenting were significant predictors of foster children's prosocial behavior. Foster children in kinship foster families showed more prosocial behavior than children in non-kinship families. This finding is in line with the positive findings for kinship families that have been shown by others (see Winokur et al. 2018 for a review and meta-analysis). The finding that positive parenting is positively related to prosocial behavior might be explained by a social learning mechanism. Foster children may learn to act prosocial by observing the positive and prosocial behaviors as modelled by their foster parents (Bandura and Walters 1977). The finding that positive parenting is predictive of foster children's prosocial behavior is hopeful because it could indicate that foster parents can boost their foster children's development through positive parenting. This is a reassuring finding and in line with the positive effects of intervention programs on parent outcomes and child problems (Schoemaker et al. 2019).

Regarding internalizing and externalizing behaviors, we found no other predictors than foster parent stress besides the age of the children. The effect of age differed for internalizing and externalizing behaviors. Older children showed more internalizing behaviors and fewer externalizing problems compared to younger children. Although this result is in line with the broader child mental health prevalence literature (e.g., Bongers et al. 2003), the latter effect is still surprising because most studies on foster children suggest that older foster children show more internalizing as well as externalizing problems (Armsden et al. 2000; Dubowitz et al. 1993; Heflinger et al. 2000; Maaskant et al. 2014). However, not all studies found the same effect of age on externalizing behaviors. For example, in a longitudinal study among adolescents aged 13 to 16, McWey et al. (2010) found that older adolescents demonstrated lower levels of both externalizing and internalizing problems. Moreover, Vanderfaeillie et al. (2013) did not find any age effect at all. Possible explanations for the different findings could be the focus on a different age range (McWey et al. 2010) or the inclusion of other predictors confounded with age such as age of entry into care (Tarren-Sweeney 2008). One last explanation for the negative effect of age on externalizing behaviors in our sample might be related to the characteristics of our sample. Our sample consisted of a group of foster children in relatively stable and long-term placements. On average, the foster children in this study resided for almost five years in their current foster placement. Because especially age and externalizing behaviors (Konijn et al. 2019; Oosterman et al. 2007), are related to placement breakdown, it could be that the group of older foster children showing externalizing behavior was underrepresented in our sample.

The characteristics of our sample might also explain why we did not find an effect of placement history on foster children's mental health. Several previous studies suggest that placement history (i.e., the number of previous placements) is one of the strongest predictors of foster children's mental health (Newton et al. 2000; Rubin et al. 2007). However, our marker of placement stability did not include how long the child was in care, because this information was often unknown to foster parents. Although we did not find a significant correlation between placement duration and placement history in our sample, it could be that children who are longer in care experienced more changes of placement. Our result that placement history is not related to children's mental health outcomes should therefore be interpreted with caution because it might apply only to foster children in relatively stable and long-term placement and without a volatile placement history. 


\section{Limitations and Directions for Future Research}

This study aimed to provide a better insight in which characteristics are related to foster children's mental health, using a three-wave longitudinal design. In the current study foster parents were the sole informants. Future research should include multiple informants or sources of information. This way, same method variance, which might result in an overestimation of the association between the variables of interest, can be prevented (Brannick et al. 2010). Furthermore, it is necessary to consider other measures than self-reports. For example, foster parents' cortisol levels could be used as a biological measure of stress. In addition, foster children's mental health could be measured by observational measures or teacher or self-reports (Boada 2007; McAuley and Trew 2000; Shore et al. 2002). Including multiple informants and different measures of the same construct would allow for a replication and validation of previous study findings.

The current study covered foster children's development over a one-year period, measured during three waves separated by six month intervals. We had a considerable amount of missing data due to attrition between waves. Our efforts to prevent attrition, for example by using incentives and sending several reminders, unfortunately had only limited effect. Although we compared our final sample with the group that dropped out after Wave I on several important characteristics and found only two significant differences, we cannot exclude the possibility that there are important differences between those who continued to participate and those who dropped out on variables that were not measured. Attrition is a common problem within longitudinal research, and longitudinal studies on foster care are not an exception (Jackson et al. 2012). Strategies for longitudinal research with foster children as described by Jackson et al. (2012) are helpful to prevent attrition in longitudinal designs. Example strategies mentioned by Jackson et al. (2012) are ensuring positive data collection experiences at one time point to prevent attrition for the next time point. If eventually, however, attrition remains high, researchers should be transparent in reporting their missing data, and should apply modern methods to handle missing data (Graham 2009), such as multiple imputation or FIML estimation.

A last point for future research is to more thoroughly examine the developmental processes and dynamic systems (i.e., interactions) of foster children and foster care. Collecting more intensive, longitudinal data with many measurements over time could provide new insights. For example, such an approach might considerably improve the opportunity to study inter-individual variability in intra-individual patterns of change (or development) over time.

\section{Conclusions}

The aim of this study was to establish what accounts for the differences in foster children's mental health outcomes. Knowledge regarding foster children's mental health outcomes and its predictors could provide valuable information to inform the design of targeted interventions and support services for foster children and foster families. The strength of our study was the use of a multivariate model in which characteristics of the foster child, the child's care experiences, foster family and foster placement were included as predictors of foster children's mental health. Among these different characteristics, foster parent stress appeared to be the most important predictor of foster children's mental health. In our study, a considerable number of foster parents showed 'above average' parenting stress levels 
(approximately 40\%). This is worrisome given the relation we found with foster children's mental health. Additionally, we also know that foster parent stress may negatively impact their motivation to continue fostering and may lead to foster parent burnout and placement disruption (Leathers et al. 2019). Therefore, it seems important to consider foster parent stress in screening and interventions, as a possible point of attention in creating conditions conducive to foster children's mental health. In addition, targeting the source of stress might be helpful in this effort. Previous research showed that foster children's challenging behaviors are perceived as very stressful by foster parents and contribute most to their stress levels (McKeough et al. 2017). A recent meta-analysis shows promising effects of foster care interventions on parenting stress $(g=0.60)$ and foster children's behavior problems $(g=0.53)$ (Schoemaker et al. 2019). Our study pointing out foster parent stress as a key factor related to foster children's mental health, the promising findings of the metaanalysis of Schoemaker et al. (2019) regarding the efficacy of interventions in reducing foster parent stress, and the fact that foster parents themselves express a desire for additional training (McKeough et al. 2017) should provide a clear signal to policymakers and professionals to improve foster parent support and training for better placement outcomes.

\section{Acknowledgements None.}

\section{Compliance with Ethical Standards}

Conflict of interest The authors declare that they have no conflict of interest.

Open Access This article is licensed under a Creative Commons Attribution 4.0 International License, which permits use, sharing, adaptation, distribution and reproduction in any medium or format, as long as you give appropriate credit to the original author(s) and the source, provide a link to the Creative Commons licence, and indicate if changes were made. The images or other third party material in this article are included in the article's Creative Commons licence, unless indicated otherwise in a credit line to the material. If material is not included in the article's Creative Commons licence and your intended use is not permitted by statutory regulation or exceeds the permitted use, you will need to obtain permission directly from the copyright holder. To view a copy of this licence, visit http://creativecommons.org/licenses/by/4.0/.

\section{References}

Abidin, R. R., \& Abidin, R. R. (1990). Parenting Stress Index (PSI). Charlottesville, VA: Pediatric Psychology Press.

Achenbach, T. M., Becker, A., Döpfner, M., Heiervang, E., Roessner, V., Steinhausen, H., et al. (2008). Multicultural assessment of child and adolescent psychopathology with ASEBA and SDQ instruments: Research findings, applications, and future directions. Journal of Child Psychology and Psychiatry, 49(3), 251-275.

Ahmad, A., Qahar, J., Siddiq, A., Majeed, A., Rasheed, J., Jabar, F., et al. (2005). A 2-year follow-up of orphans' competence, socioemotional problems and post-traumatic stress symptoms in traditional foster care and orphanages in Iraqi Kurdistan. Child: Care, Health and Development, 31(2), 203-215.

Ainsworth, F., \& Hansen, P. (2014). Family foster care: Can it survive the evidence? Children Australia, $39(2), 87-92$.

Andersen, A., Krølner, R., Currie, C., Dallago, L., Due, P., Richter, M., et al. (2008). High agreement on family affluence between children's and parents' reports: International study of 11-year-old children. Journal of Epidemiology \& Community Health, 62(12), 1092-1094.

Armsden, G., Pecora, P. J., Payne, V. H., \& Szatkiewicz, J. P. (2000). Children placed in long-term foster care: An intake profile using the Child Behavior Checklist/4-18. Journal of Emotional and Behavioral Disorders, 8(1), 49-64. 
Azur, M. J., Stuart, E. A., Frangakis, C., \& Leaf, P. J. (2011). Multiple imputation by chained equations: What is it and how does it work? International Journal of Methods in Psychiatric Research, 20(1), 40-49.

Bandura, A., \& Walters, R. H. (1977). Social learning theory (Vol. 1). Englewood Cliffs, NJ: Prentice-Hall.

Barber, J., \& Delfabbro, P. (2005). Children's adjustment to long-term foster care. Children and Youth Services Review, 27(3), 329-340.

Boada, C. M. (2007). Kinship foster care: A study from the perspective of the caregivers, the children and the child welfare workers. Psychology in Spain, 11(1), 42-52.

Boyce, W., Torsheim, T., Currie, C., \& Zambon, A. (2006). The family affluence scale as a measure of national wealth: Validation of an adolescent self-report measure. Social Indicators Research, 78(3), 473-487.

Bowlby, J. (1969). Attachment and loss: Attachement (Vol. I). London: The Tavistock Institute of Human Relations.

Brannick, M. T., Chan, D., Conway, J. M., Lance, C. E., \& Spector, P. E. (2010). What is method variance and how can we cope with it? A panel discussion. Organizational Research Methods, 13(3), 407-420.

Chamberlain, P., Price, J., Leve, L. D., Laurent, H., Landsverk, J. A., \& Reid, J. B. (2008). Prevention of behavior problems for children in foster care: Outcomes and mediation effects. Prevention Science, 9(1), 17-27.

Cicchetti, D., Toth, S. L., \& Maughan, A. (2000). An ecological-transactional model of child maltreatment. In A. J. Sameroff, M. Lewis \& S. M. Miller (Eds.), Handbook of developmental psychopathology (pp. 689-722). Boston, MA: Springer.

Clausen, J. M., Landsverk, J., Ganger, W., Chadwick, D., \& Litrownik, A. (1998). Mental health problems of children in foster care. Journal of Child and Family Studies, 7(3), 283-296.

Cooley, M. E., Thompson, H. M., \& Newell, E. (2019). Examining the influence of social support on the relationship between child behavior problems and foster parent satisfaction and challenges. Child \& Youth Care Forum, 48(3), 289-303.

Cuddeback, G. S. (2004). Kinship family foster care: A methodological and substantive synthesis of research. Children and Youth Services Review, 26(7), 623-639. https://doi.org/10.1016/J.CHILD YOUTH.2004.01.014.

Currie, C. E., Elton, R. A., Todd, J., \& Platt, S. (1997). Indicators of socioeconomic status for adolescents: The WHO Health Behaviour in School-aged Children Survey. Health Education Research, 12(3), 385-397.

Dadds, M. R., Maujean, A., \& Fraser, J. A. (2003). Parenting and conduct problems in children: Australian data and psychometric properties of the Alabama Parenting Questionnaire. Australian Psychologist, 38(3), 238-241.

De Brock, A., Vermulst, A. A., Gerris, J. R. M., \& Abidin, R. R. (1992). NOSI: Nijmeegse ouderlijke stress index. Lisse: Swets En Zeitlinger.

Dixon, J. (2008). Young people leaving care: Health, well-being and outcomes. Child \& Family Social Work, 13(2), 207-217.

Dozier, M., Kaufman, J., Kobak, R., O’Connor, T. G., Sagi-Schwartz, A., Scott, S., et al. (2014). Consensus statement on group care for children and adolescents: A statement of policy of the American Orthopsychiatric Association. American Journal of Orthopsychiatry, 84(3), 219.

Dubowitz, H., Zuravin, S., Starr, R. H., Feigelman, S., \& Harrington, D. (1993). Behavior problems of children in kinship care. Journal of Developmental and Behavioral Pediatrics, 14(6), 386-393.

Elgar, F. J., Waschbusch, D. A., Dadds, M. R., \& Sigvaldason, N. (2007). Development and validation of a short form of the Alabama Parenting Questionnaire. Journal of Child and Family Studies, 16(2), 243-259.

Enders, C. K., \& Tofighi, D. (2007). Centering predictor variables in cross-sectional multilevel models: A new look at an old issue. Psychological Methods, 12(2), 121.

Fanshel, D., \& Shinn, E. B. (1978). Children in foster care: A longitudinal investigation. New York: Columbia University Press.

Fernandez, E. (2009). Children's wellbeing in care: Evidence from a longitudinal study of outcomes. Children and Youth Services Review, 31(10), 1092-1100.

Frank, G. (1980). Treatment needs of children in foster care. American Journal of Orthopsychiatry, 50(2), 256.

Frick, P. J. (1991). The Alabama parenting questionnaire. Unpublished Rating Scale, University of Alabama.

Gabler, S., Kungl, M., Bovenschen, I., Lang, K., Zimmermann, J., Nowacki, K., et al. (2018). Predictors of foster parents' stress and associations to sensitivity in the first year after placement. Child Abuse \& Neglect, 79, 325-338. 
Goemans, A., Van Geel, M., Van Beem, M., \& Vedder, P. (2016a). Developmental outcomes of foster children: A meta-analytic comparison with children from the general population and children at risk who remained at home. Child Maltreatment, 21(3), 198-217.

Goemans, A., Van Geel, M., \& Vedder, P. (2015). Over three decades of longitudinal research on the development of foster children: A meta-analysis. Child Abuse \& Neglect, 42, 121-134.

Goemans, A., Van Geel, M., \& Vedder, P. (2016b). Psychosocial functioning in Dutch foster children: The relationship with child, family, and placement characteristics. Child Abuse \& Neglect, 56, 30-43.

Goemans, A., Van Geel, M., \& Vedder, P. (2018a). Foster children's behavioral development and foster parent stress: Testing a transactional model. Journal of Child and Family Studies, 27(3), 990-1001.

Goemans, A., Van Geel, M., Wilderjans, T. F., Van Ginkel, J. R., \& Vedder, P. (2018b). Predictors of school engagement in foster children: A longitudinal study. Children and Youth Services Review, 88, 33-43.

Goodman, A., Lamping, D. L., \& Ploubidis, G. B. (2010). When to use broader internalising and externalising subscales instead of the hypothesised five subscales on the Strengths and Difficulties Questionnaire (SDQ): Data from British parents, teachers and children. Journal of Abnormal Child Psychology, 38(8), 1179-1191.

Goodman, R. (1997). The Strengths and Difficulties Questionnaire: A research note. Journal of Child Psychology and Psychiatry, 38(5), 581-586.

Graham, J. W. (2009). Missing data analysis: Making it work in the real world. Annual Review of Psychology, 60, 549-576.

Groothuis-Oudshoorn, K., \& Van Buuren, S. (2011). Mice: Multivariate imputation by chained equations in R. Journal of Statistical Software, 45(3), 1-67.

Grund, S., Lüdtke, O., \& Robitzsch, A. (2016). Multiple imputation of multilevel missing data: An introduction to the R package pan. SAGE Open, 6(4), 2158244016668220.

Haskett, M. E., Ahern, L. S., Ward, C. S., \& Allaire, J. C. (2006). Factor structure and validity of the parenting stress index-short form. Journal of Clinical Child \& Adolescent Psychology, 35(2), 302-312.

Heflinger, C. A., Simpkins, C. G., \& Combs-Orme, T. (2000). Using the CBCL to determine the clinical status of children in state custody. Children and Youth Services Review, 22(1), 55-73.

Heymans, W. M., \& Eekhout, I. (2019). Applied missing data analysis with SPSS and (R)Studio. Retrieved from https://bookdown.org/mwheymans/bookmi/.

Hiller, R. M., \& Clair, M. C. S. (2018). The emotional and behavioural symptom trajectories of children in long-term out-of-home care in an English local authority. Child Abuse \& Neglect, 81, 106-117.

Holtan, A., Rønning, J. A., Handegård, B. H., \& Sourander, A. (2005). A comparison of mental health problems in kinship and nonkinship foster care. European Child \& Adolescent Psychiatry, 14(4), 200-207. https://doi.org/10.1007/s00787-005-0445-z.

Jackson, Y., Gabrielli, J., Tunno, A. M., \& Hambrick, E. P. (2012). Strategies for longitudinal research with youth in foster care: A demonstration of methods, barriers, and innovations. Children and Youth Services Review, 34(7), 1208-1213.

Kelley, S. J., Whitley, D. M., \& Campos, P. E. (2011). Behavior problems in children raised by grandmothers: The role of caregiver distress, family resources, and the home environment. Children and Youth Services Review, 33(11), 2138-2145.

Konijn, C., Admiraal, S., Baart, J., van Rooij, F., Stams, G.-J., Colonnesi, C., et al. (2019). Foster care placement instability: A meta-analytic review. Children and Youth Services Review, 96, 483-499.

Lawrence, C. R., Carlson, E. A., \& Egeland, B. (2006). The impact of foster care on development. Development and Psychopathology, 18(1), 57-76.

Leathers, S. J., Spielfogel, J. E., Geiger, J., Barnett, J., \& Voort, B. L. V. (2019). Placement disruption in foster care: Children's behavior, foster parent support, and parenting experiences. Child Abuse \& Neglect, 91, 147-159.

Leathers, S. J., Spielfogel, J. E., McMeel, L. S., \& Atkins, M. S. (2011). Use of a parent management training intervention with urban foster parents: A pilot study. Children and Youth Services Review, 33(7), 1270-1279.

Lehmann, S., Havik, O. E., Havik, T., \& Heiervang, E. R. (2013). Mental disorders in foster children: A study of prevalence, comorbidity and risk factors. Child and Adolescent Psychiatry and Mental Health, $7(1), 39$.

Li, D., Chng, G. S., \& Chu, C. M. (2017). Comparing long-term placement outcomes of residential and family foster care: A meta-analysis. Trauma, Violence, \& Abuse, 1524838017726427.

Lohaus, A., Kerkhoff, D., Chodura, S., Möller, C., Symanzik, T., Rueth, J. E., et al. (2018). Longitudinal relationships between foster children's mental health problems and parental stress in foster mothers and fathers. European Journal of Health Psychology, 25(2), 33-42.

Maaskant, A. M. (2016). Placement breakdown in foster care: Reducing risks by a foster parent training program? Universiteit van Amsterdam. 
Maaskant, A. M., van Rooij, F. B., \& Hermanns, J. M. A. (2014). Mental health and associated risk factors of Dutch school aged foster children placed in long-term foster care. Children and Youth Services Review, 44, 207-216. https://doi.org/10.1016/J.CHILDYOUTH.2014.06.011.

Maaskant, A. M., van Rooij, F. B., Overbeek, G. J., Oort, F. J., \& Hermanns, J. M. A. (2016). Parent training in foster families with children with behavior problems: Follow-up results from a randomized controlled trial. Children and Youth Services Review, 70, 84-94.

McAuley, C., \& Trew, K. (2000). Children's adjustment over time in foster care: Cross-informant agreement, stability and placement disruption. British Journal of Social Work, 30(1), 91-107.

McKeough, A., Bear, K., Jones, C., Thompson, D., Kelly, P. J., \& Campbell, L. E. (2017). Foster carer stress and satisfaction: An investigation of organisational, psychological and placement factors. Children and Youth Services Review, 76, 10-19.

McSherry, D. (2018). Remembering what the big friendly giants said: To understand outcomes, you first need to understand context. Children Australia, 43(2), 91-94.

McSherry, D., Fargas Malet, M., \& Weatherall, K. (2018). The Strengths and Difficulties Questionnaire (SDQ): A proxy measure of parenting stress. The British Journal of Social Work, 49(1), 96-115.

McSherry, D., \& Malet, M. F. (2017). Family foster care: Let's not throw the baby out with the bathwater. Children Australia, 42(3), 217-221.

McWey, L. M., Cui, M., \& Pazdera, A. L. (2010). Changes in externalizing and internalizing problems of adolescents in foster care. Journal of Marriage and Family, 72(5), 1128-1140.

Muris, P., Meesters, C., \& van den Berg, F. (2003). The strengths and difficulties questionnaire (SDQ). European Child \& Adolescent Psychiatry, 12(1), 1-8.

Murray, L., Tarren-Sweeney, M., \& France, K. (2011). Foster carer perceptions of support and training in the context of high burden of care. Child \& Family Social Work, 16(2), 149-158.

Newton, R. R., Litrownik, A. J., \& Landsverk, J. A. (2000). Children and youth in foster care: Disentangling the relationship between problem behaviors and number of placements. Child Abuse \& Neglect, 24(10), 1363-1374. https://doi.org/10.1016/S0145-2134(00)00189-7.

Nilsen, W. (2007). Fostering futures: A preventive intervention program for school-age children in foster care. Clinical Child Psychology and Psychiatry, 12(1), 45-63.

Oosterman, M., Schuengel, C., Slot, N. W., Bullens, R. A. R., \& Doreleijers, T. A. H. (2007). Disruptions in foster care: A review and meta-analysis. Children and Youth Services Review, 29(1), 53-76.

Perkins, J. N. (2008). Foster parenting practices as predictors of foster child outcomes. University of Ottawa (Canada).

Peugh, J. L. (2010). A practical guide to multilevel modeling. Journal of School Psychology, 48(1), 85-112.

Roy, P., Rutter, M., \& Pickles, A. (2000). Institutional care: Risk from family background or pattern of rearing? The Journal of Child Psychology and Psychiatry and Allied Disciplines, 41(2), 139-149.

Rubin, D. B. (1987). Multiple imputation for nonresponse in surveys. New York: Wiley.

Schafer, J. L., \& Graham, J. W. (2002). Missing data: Our view of the state of the art. Psychological Methods, $7(2), 147$.

Schoemaker, N. K., Wentholt, W. G. M., Goemans, A., Vermeer, H. J., Juffer, F., \& Alink, L. R. A. (2019). A meta-analytic review of parenting interventions in foster care and adoption. Development and Psychopathology. https://doi.org/10.1017/S0954579419000798.

Stott, T., \& Gustavsson, N. (2010). Balancing permanency and stability for youth in foster care. Children and Youth Services Review, 32(4), 619-625.

Shelton, K. K., Frick, P. J., \& Wootton, J. (1996). Assessment of parenting practices in families of elementary school-age children. Journal of Clinical Child Psychology, 25(3), 317-329.

Shore, N., Sim, K. E., Le Prohn, N. S., \& Keller, T. E. (2002). Foster parent and teacher assessments of youth in kinship and non-kinship foster care placements: Are behaviors perceived differently across settings? Children and Youth Services Review, 24(1-2), 109-134.

Singer, J. D., Willett, J. B., \& Willett, J. B. (2003). Applied longitudinal data analysis: Modeling change and event occurrence. Oxford: Oxford University Press.

Stone, N. M., \& Stone, S. F. (1983). The prediction of successful foster placement. Social Casework, 64(1), 11-17.

Tabachnick, B. G., Fidell, L. S., \& Ullman, J. B. (2007). Using multivariate statistics (Vol. 5). Boston, MA: Pearson.

Tarren-Sweeney, M. (2008). Retrospective and concurrent predictors of the mental health of children in care. Children and Youth Services Review, 30(1), 1-25.

Tarren-Sweeney, M. (2017). Rates of meaningful change in the mental health of children in long-term outof-home care: A seven-to nine-year prospective study. Child Abuse \& Neglect, 72, 1-9. 
Tarren-Sweeney, M. T., \& Goemans, A. (2019). A narrative review of stability and change in the mental health of children who grow up in family-based out-of-home care. Developmental Child Welfare, 1(3), 273-294.

Team, R. C. (2018). R: A language and environment for statistical computing; 2015.

Tizard, B., \& Hodges, J. (1978). The effect of early institutional rearing on the development of eight year old children. Journal of Child Psychology and Psychiatry, 19(2), 99-118.

Van Andel, H. W. H., Post, W. J., Jansen, L. M. C., Kamphuis, J. S., Van der Gaag, R. J., Knorth, E. J., et al. (2015). The developing relationship between recently placed foster infants and toddlers and their foster carers: Do demographic factors, placement characteristics and biological stress markers matter? Children and Youth Services Review, 58, 219-226.

Van Ginkel, J. R., Linting, M., Rippe, R. C., \& van der Voort, A. (2019). Rebutting existing misconceptions about multiple imputation as a method for handling missing data. Journal of Personality Assessment. https://doi.org/10.1080/00223891.2018.1530680.

Van Lier, P. A. C., \& Crijnen, A. A. M. (1999). Alabama parenting questionnaire, Nederlandse vertaling [Alabama Parenting Questionnaire, Dutch translation]. Unpublished Manuscript.

Van Oijen, S. (2010). Resultaat van pleegzorgplaatsingen: Een onderzoek naar breakdown en de ontwikkeling van adolescente pleegkinderen bij langdurige pleegzorgplaatsingen. University of Groningen.

Van Widenfelt, B. M., Goedhart, A. W., Treffers, P. D. A., \& Goodman, R. (2003). Dutch version of the Strengths and Difficulties Questionnaire (SDQ). European Child \& Adolescent Psychiatry, 12(6), 281-289.

Vanderfaeillie, J., Van Holen, F., Vanschoonlandt, F., Robberechts, M., \& Stroobants, T. (2013). Children placed in long-term family foster care: A longitudinal study into the development of problem behavior and associated factors. Children and Youth Services Review, 35(4), 587-593. https://doi.org/10.1016/J. CHILDYOUTH.2012.12.012.

Winokur, M. A., Holtan, A., \& Batchelder, K. E. (2018). Systematic review of kinship care effects on safety, permanency, and well-being outcomes. Research on Social Work Practice, 28(1), 19-32.

Publisher's Note Springer Nature remains neutral with regard to jurisdictional claims in published maps and institutional affiliations. 